\title{
FEASIBILITY ANALYSIS OF CULTIVATED BERRY FIELD LAYOUT FOR AUTOMATED CULTIVATION
}

\author{
Kaarel Soots, Tormi Lillerand, Erkki Jogi, Indrek Virro, Juri Olt \\ Estonian University of Life Sciences, Estonia \\ kaarel.soots@emu.ee, tormi.lillerand@emu.ee,erkki.jogi@emu.ee,indrek.virro@emu.ee, \\ jyri.olt@emu.ee
}

\begin{abstract}
Automation is a solution, which can be used by modern farmers to aid them in reducing manpower requirements in the fields. There are currently a number of development teams, which are making strides towards the development of automated solutions for operations which are related to various agricultural tasks. When possible, electric drives are used as motors for automated field robots. Fields are usually located in remote areas with no easily-available power grid to which to connect. Instead, locally-produced electrical energy from a renewable source is used to charge the batteries of field robots. Automated equipment which is operating in fields could benefit from the addition of what, in essence, is a service station, which could take care of the following tasks: 1) transporting field robots and all the necessary accessories, goods, fertiliser, plant protection products, and so on into the field; 2) electrical energy generation and accumulation; 3 ) charging the batteries for the field robots; 4) filling the tanks of the field robots; 5) ensuring communications with the field robot or a swarm of such robots, and between the farmer and remote databases. The aim of this article was to study the suitability of existing cultivated berry fields in terms of being able to apply a solution, which involves automation and precision cultivation, with the continued operability of such automation being ensured by the presence of a service station. In order to be able to fulfil the aims of this article, the initial data that weere collected in relation to the berry plantation, plus the specific berry cultivar and field robot type, will all be presented here. A discussion will be held in terms of suitable solutions for the supply of electrical energy to automated berry fields and, as a result of processing the collected data, proposals will be made for the layout of the crops, the layout and location of the service station, and also the trajectory of the field robot in the field itself.
\end{abstract}

Keywords: robotisation; renewable energy; agricultural robotics; precision fertilising; product development.

\section{Introduction}

Automation by means of field robots is a solution, which will permit farmers to reduce manpower requirements in fields when it comes to seasonal operations. Manpower is currently required in relation to a good many types of crop, and seasonal operations such as fertilisation, spraying, or harvesting can increase the need for manpower on a seasonal basis. One such operation, which, seasonally, requires more manpower, is that of cultivating blueberries. The Estonian University of Life Sciences has studied cultivated blueberries [1;2], the cultivation practices behind them [3-5], and the establishment of cultivated blueberry plantations on exhausted milled peat fields [6-8]. The use of field robots makes it possible to increase the implementation of precision farming, which, in turn, reduces the cost of products, which are required to be sprayed onto crops, and increases the profitability of the plantations [9]. The applicability of machine cultivation $[10 ; 11]$ and also automated precision farming technology, when it comes to blueberry plantations, which have been established on exhausted milled peat fields $[12 ; 13]$, as well as post-harvest processing technology in relation to blueberries [14; 15], have also been studied at the Estonian University of Life Sciences. Today a number of teams are undertaking various efforts to develop automation in operations that are related to various agricultural tasks, such as fertilisation, weeding, harvesting, and more $[16 ; 17]$. The applicability of field robots is an area that is being widely studied, for example, in terms of the cultivation and harvesting of various fruits, roots, vegetables, and cereals [18]. In addition, studies have also been conducted in terms of the applicability of field robots to be able to transport already-harvested crops [19]. Fields are usually located in remote areas for which power lines are unavailable, but where electricity is still essential, when it comes to charging the batteries on the field robots.

The aim of this article was to study the suitability of existing cultivated berry fields in terms of being able to apply a solution, which involves automation and precision cultivation, with the continued operability of such automation being ensured by the presence of a service station.

To fulfil the aims of the article the following tasks were set out:

1. Identify initial data regarding the crop, the field, and the field robot that is being developed.

2. Investigate the arrangement of plantation areas and sites which have turning strips. 
3. Investigate the logistics involved in using a field robot in the plantation.

4. Investigate the possible siting of the service station.

The information that is presented in this article provides the basis for further stages in the development of the service station.

\section{Materials and methods}

\section{Field robot}

The Institute of Technology at the Estonian University of Life Sciences is engaged in the development of a field robot, which, when complete, will be able to care for cultivated plants. The design conditions for such a field robot, which is under development here, are as follows [12]:

1. Task: fertilisation with granular and liquid fertilisers and spraying with a plant protection product;

2. Overall dimensions: length $l_{r}=2200 \mathrm{~mm}$, width $w_{r}=1020 \mathrm{~mm}$ and height $h_{r}=1750 \mathrm{~mm}$;

3. Total weight of the field robot with a full fuel tank: $m_{r}=350 \mathrm{~kg}$;

4. Specific pressure applied to the soil by the field robot: $E_{r}=0.022 \mathrm{~N} \cdot \mathrm{mm}^{-2}$;

5. Turning radius: $r_{r}=1.5 \mathrm{~m}$.

\section{Cultivated berry plantation}

The description of the cultivated berry plantation used here has its basis in Toomas Jaadla's Marjasoo Farm in Vehendi Village, Elva Municipality, Tartu County (GPS 58.200155259628524, 26.13624544067728), which was surveyed using the Land Board's map application [20].

The cultivated blueberry varieties at Marjasoo Farm were selected as the cultivated berry type to be used here, details for which are as follows:

1. Cultivated blueberry varieties: the narrow-leaved blueberry cultivars, 'North' and 'Northblue' [21];

2. Planting density for crop plants is as follows: plant spacing in a row $d_{p}=1.4 \mathrm{~m}$, and row spacing $w_{p}=1.4 \mathrm{~m}[12 ; 13]$;

3. The mean height of plants: $h_{p}=220 \mathrm{~mm}$ (biennial plants) [13];

4. The dimensions of the plant leafage: $b_{p}=180 \pm 84 \mathrm{~mm}$ and $c_{p}=189 \pm 87 \mathrm{~mm}$ (the shape of a blueberry plant treated as a rectangle) [13];

5. Granular fertiliser for cultivated blueberries: SQM fertiliser Qrop complex, and Top K 12-6-24 [22].

\section{Results and discussion}

Using the Land Board's map application, areas were measured across the cultivated berry fields, as shown in Fig. 1.

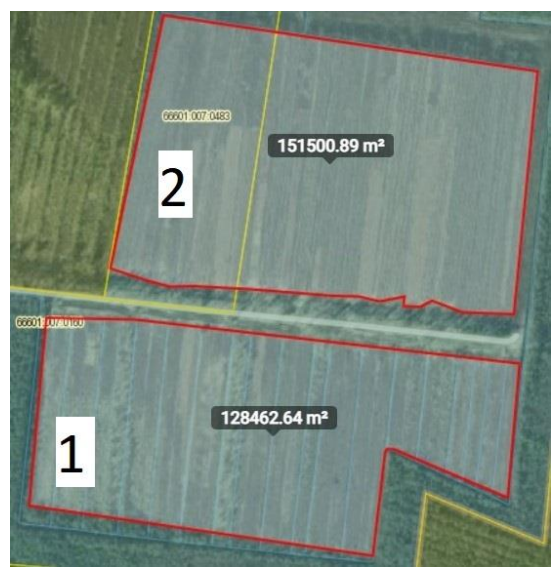

Fig. 1. Marjasoo Farm: 1 - southern field; 2 - northern field [20]

The total rounded-up size of the plantation at Marjasoo Farm was measured at $s_{m}=28 \mathrm{ha}$, on the basis of the Land Board's map application. The plantation has been established on an exhausted milled peat field, one which is suitable for growing cultivated blueberries [15, 23]. Said plantation is divided into a northern and a southern field, as shown in Fig. 1, and the fields are in turn divided into sections, 
with drainage ditches between the sections. The widths of each of these sections were measured using the Land Board's map application, as shown in Fig. 2, and the lengths of the plant rows in each section are shown in Fig. 3.

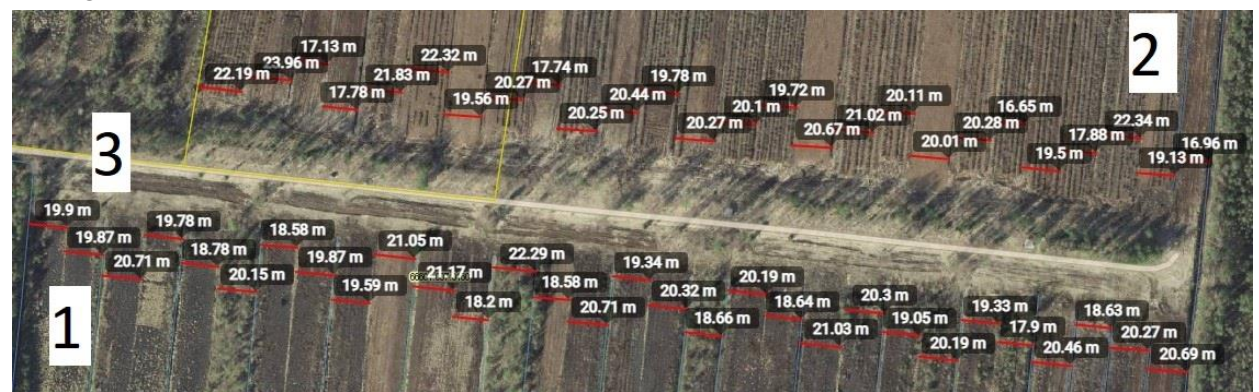

Fig. 2. Widths of sections on the plantation on Marjasoo Farm: 1 - southern field; 2 - northern field; 3 - service road [20]

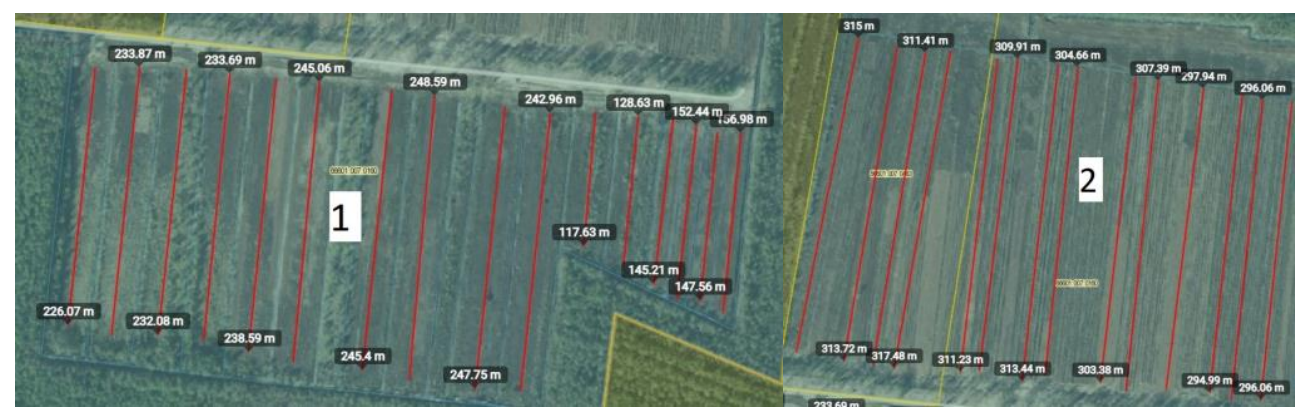

Fig. 3. Lengths of sections on the plantation at Marjasoo Farm: 1 - southern field; 2 - northern field [20]

As it can be seen in Figs. 1 and 2, there is a service road between the southern and northern fields on the plantation at Marjasoo Farm, which can be used for various service needs, such as, for example, to transport the service station to its resting location. Between the service road and the plant rows in the fields there is a service area, one in the northern and southern fields, with dimensions that are shown in Fig. 4.

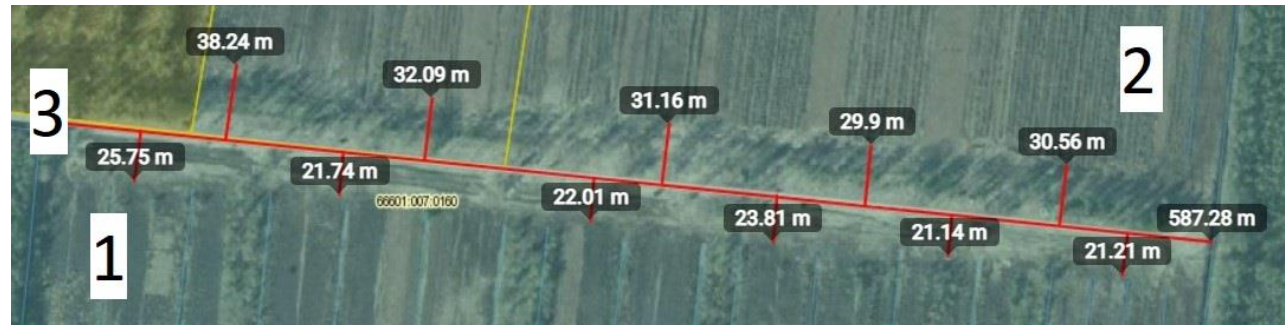

Fig. 4. Service areas in the plantation on Marjasoo Farm: 1 - southern field; 2 - northern field; 3 service road [20]

Based on the information that has been obtained from the Land Board's map application, it was discovered that it is not always possible for a field robot to use a loop-like reversal trajectory when changing rows, because there is not enough space for such a manoeuvre at the end of the plant row. Instead, in mitigation, the field robot will have to make a quarter turn, then reverse, and finally make another quarter turn. In summary, the information which serves to describe the plantation at Marjasoo Farm can be laid out as follows:

1. Field soil: boggy surface, depleted milled peat field [21];

2. Soil-bearing capacity: $0.07-0.08 \mathrm{~N} \cdot \mathrm{mm}^{-2}$ [25];

3. Exposure of the fields to the sun: the central area of each sections is open, with single trees or a forest at the edges of the fields or single trees between the sections [20];

4. Maximum and minimum dimensions for field sections, with each being rounded: length:

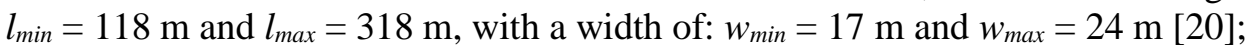


5. Average pitch of field sections: $w_{s}=20 \mathrm{~m}$, which is considered to be the standard width for a field section in milling peat production fields [20;24];

6. Crops grown in the fields: cranberries, blueberries, and lingonberries [21];

7. Technical tracks in the fields: width $w_{t r}=1.5 \mathrm{~m} \mathrm{[13];}$

8. Service areas in the fields: at the roadside end of the beds, with a length of $l_{s a}=587.28 \mathrm{~m}$ and a minimum width (rounded) of $w_{s r}=21 \mathrm{~m} \mathrm{[20].}$

Due to the requirement imposed on the service station to be able to generate the required amount of electricity by itself, renewable energy solutions were first considered in the form of a wind generator or solar panels. Based on the specific nature of the fields, and since the field robot is being used during the spring and summer periods, solar panels were chosen as the primary source of electricity for the service station instead of a wind generator. The solar panels can be installed on the vertical and horizontal external surfaces of the service station or placed on a separate mobile platform. As the service station must be portable, it is more practical to install solar panels on the exterior of the service station. As any electricity that is produced by solar panels may not be available all the time, for example, during cloudy weather, other solutions were sought for, when it came to generating electricity in the field. An electricity generator was chosen as the secondary source of electrical supply. The electricity generator is used to supply electricity to the equipment fleet, if the battery bank on the service station is empty and the amount of electricity being produced by the solar panels is insufficient to ensure continued operations. Using liquid fuel internal combustion engines is impractical, when it comes to operating the electric generator, while taking into account the inconvenience of handling the fuel and ensuring environmental safety requirements. Therefore, a LPG fuelled motor with the AC generator should be used as a secondary source of electrical generation for the service station.

Based on the information that has been obtained from the available sources and the field observations that have been carried out by the authors of the paper, in order to automate the cultivation of blueberries, the cultivated blueberry plants should be placed in the field as shown in Fig. 5.

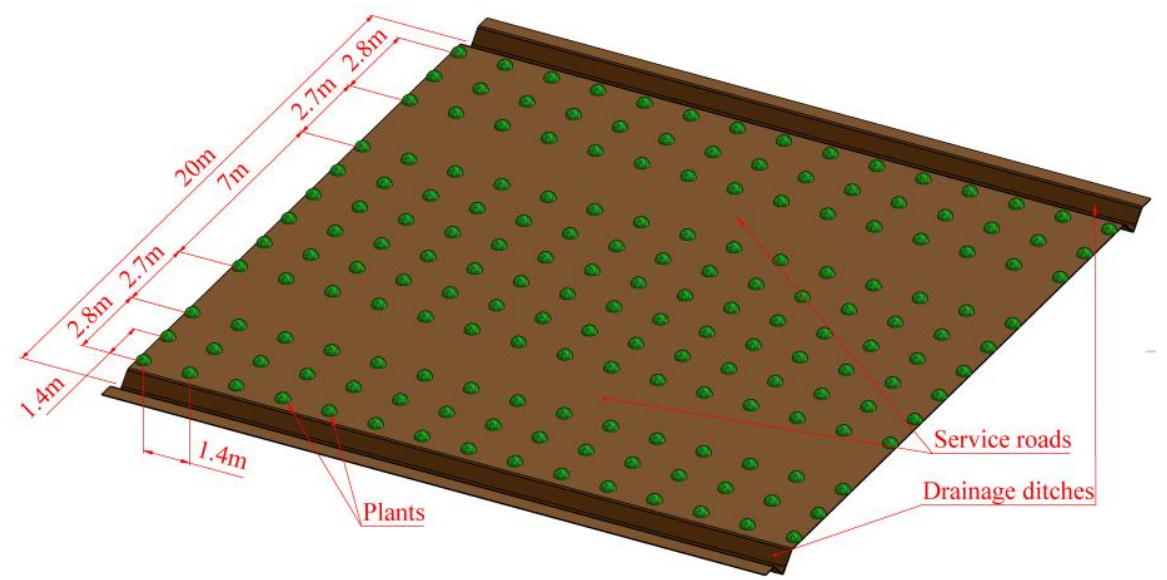

Fig. 5. Crop locations suitable for automated cultivation in the blueberry plantation

Fig. 5 indicates that three beds can be formed in the area between the drainage ditches, with a width of $w_{s}=20 \mathrm{~m}$, of which the two side beds have three rows of cultivated blueberry plants and the central one has six rows of cultivated blueberry plants. Between the middle bed and both side beds, two service roads can be designed with a width of $2.7 \mathrm{~m}$, which are necessary for automated cultivation operations. As stated, the width of the service road is $2.7 \mathrm{~m}$, which seems somewhat oversized at the beginning, but the fact must be taken into account that, as the blueberry plants grow, the available width of the service road will decrease. In order to ensure the maximum productivity levels by the field robot, the unladen distance $s_{r t}$ must be as short as possible and, therefore, when planning operational trips for the field robot, the fact must be taken into account that the field robot works by even numbers of rows. On the basis of the previous papers [13], the planting uniformity of the existing cultivated blueberries should be improved to ensure that the field robot can properly follow the row of plants, and that the application of the product to the plants is accurate. At the moment, the dispersion of the plants in relation to the axis 
of the plant row is $660 \mathrm{~mm}$, and the planting distance for the plants from each other is between 915$1,800 \mathrm{~mm}$.

One possible location point for the service station in the field at Marjasoo Farm is shown in Fig. 6.

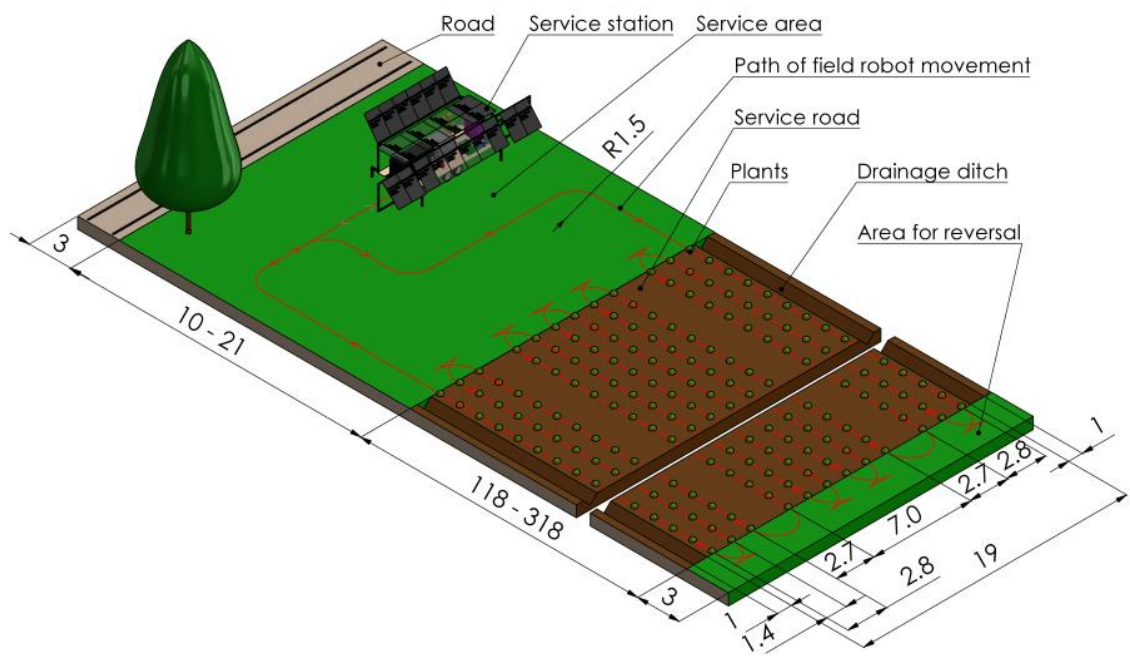

Fig. 6. Location of the service station in the field at Marjasoo Farm

The start and end points for the field robot's trajectory - as shown in the layout diagram for the service station in Fig. 6 - are located in the service station itself, which is standing in the maintenance area. The field robot makes idle runs across green areas and operational runs through the brown areas. Fig. 6 also shows the reversal trajectories for the field robot when changing rows.

\section{Conclusions}

In this article, Marjasoo Farm's cultivated blueberry plantation was used as a basis for a study into the suitability of existing cultivated berry fields, when it comes to automated and precision cultivation with a field robot. In the course of the work, initial information was collected on the field robot that was to be developed, as well as on Marjasoo Farm's blueberry plantation, and on the cultivated blueberries themselves. Based on this information, a solution was proposed in terms of the design of a field of cultivated blueberries so that it could be suitable for automated cultivation using a field robot. Upon examining the location of the fields at Marjasoo Farm, it was found that using solar panels as a renewable energy source to generate electricity in the field would be the most suitable option, and that a compressed gas-fired electricity generator would be the best alternative in order to secure a backup energy supply. The article also examined the possible location of the service station within the field and found that the maintenance areas at the end of the existing fields are suitable areas in which to place the service station. The results which have been presented in this article can be used to design fields for the automated cultivation of blueberries on depleted former milled peat fields and can also be used in the subsequent stages of the development of a service station, which include the design, manufacture, and testing of a prototype service station.

\section{References}

[1] Soots K., Krikmann O., Starast M. etc. Determining the dimensional characteristics of blueberries. Agronomy Research, vol. 15 (3), 2017, pp. 886-896.

[2] Arak M., Soots K., Starast M. etc. Mechanical properties of blueberry stems. Research in Agricultural Engineering, vol. 64, 2018, pp. 202-208.

[3] Noormets M., Karp K., Paal T. Recultivation of opencast peat pits with Vaccinium culture in Estonia. Transactions on Ecology and the Environment, vol. 64, 2003, pp. 1005-1014.

[4] Starast M., Karp K. Noormets M. The effect of foliar fertilisation on the growth and yield of lowbush blueberry in Estonia. Acta Horticulturae, vol. 594, 2002, pp. 679-684.

[5] Starast M., Karp K., Vool E. etc. Effect of NPK fertilization and elemental sulphur on growth and yield of lowbush blueberry. Agricultural and Food Science, vol. 1, 2007, pp. 34-45. 
[6] Paal T., Starast M., Noormets-Šanski M. etc. Influence of liming and fertilization on lowbush blueberry in harvested peat field condition. Scientia Horticulturae, vol. 130 (1), 2011, pp. 157-163.

[7] Starast M., Karp K., Paal T. etc. Kultuurmustikas ja selle kasvatamine (Cultural blueberries and their cultivation). Tartu: Estonian Agricultural University, 2005. 65 p. (in Estonian).

[8] Vahejõe K., Albert T., Noormets M. etc. Berry cultivation in cutover peatlands in Estonia: Agricultural and economical aspects. Baltic Forestry, vol. 16 (2), 2010, pp. 264-272.

[9] Esau T., Zaman Q., Groulx D. etc. Machine vision smart sprayer for spot-application of agrochemical in wild blueberry fields. Precision Agriculture, vol. 19 (4), 2018, pp. 770-788.

[10] Arak M., Olt J. Constructive and kinematics parameters of the picking device of blueberry harvester. Agronomy Research, vol. 12 (1), 2014, pp. 25-32.

[11] Olt J., Arak M., Jasinskas A. Development of mechanical technology for low-bush blueberry cultivating in the plantation established on milled peat fields. Agricultural Engineering, vol. 45 (2), 2013, pp. 120-131.

[12] Virro I., Arak M., Maksarov V. etc. Precision fertilisation technologies for berry plantation. Agronomy Research, vol. 18, special issue 4, 2020, pp. 2797-2810.

[13] Arak M., Olt J. Technological description for automating the cultivation of blueberries in blueberry plantations established on depleted peat milling fields. Proceedings of International Scientific Conference "Rural Development 2019", September 26-28, 2019, Kaunas, Lithuania. pp. 98-103.

[14] Soots K., Maksarov V., Olt J. Continuously adjustable berry sorter. Agronomy Research, vol. 12 (1), 2014, pp. 161-170.

[15] Soots K., Olt J. Non-stationary processing center for small and medium sized blueberry farms. Research in Agricultural Engineering, vol. 63, 2017, pp. 136-144.

[16] Bechar, A., Vigneault, C. Agricultural robots for field operations. Part 2: Operations and systems. Biosystems Engineering, vol. 153, 2017, pp. 110-128.

[17] Hayashi, S., Shigematsu, K., Yamamoto, S. etc. Evaluation of a strawberry-harvesting robot in a field test. Biosystems Engineering, vol. 105, 2010, pp. 160-171.

[18] Bechar A., Vigneault C. Agricultural robots for field operations: Concepts and components. Biosystems Engineering, vol. 149, 2016, pp. 94-111.

[19] From P.J., Grimstad L., Hanheide M. etc. RASberry: Robotic and autonomous systems: For berry production. Mechanical Engineering, vol. 140 (6), 2018, pp. 14-18.

[20] Land Board's map application. Republic of Estonia Land Board. [online] [26.02.2021]. Available at: https://xgis.maaamet.ee/xgis2/page/app/maainfo

[21] The Farm Marjasoo. [online] [26.02.2021]. Available at: https://marjasoo.ee/english

[22] SQM granular fertilizer Qrop complex Top K. [online] [26.02.2021]. Available at: https://s3-uswest-2.amazonaws.com/libqsqm/2020/01/27/194043710613.pdf

[23] Peatland Ecology Research Group. Production of berries in peatlands. Guide produced under the supervision of Line Rochefort and Line Lapointe. Quebec: Université Laval, 2009. 134 p.

[24] Estonian Peat Association. [online] [26.02.2021]. Available at: https://www.turbaliit.ee/

[25]Zwanenburg C. Full scale field tests for strength assessment of peat. Proceedings of International Conference "Soil Mechanics and Geotechnical Engineering", September 2-6, 2013, Paris, France, pp. 3329-3332. 